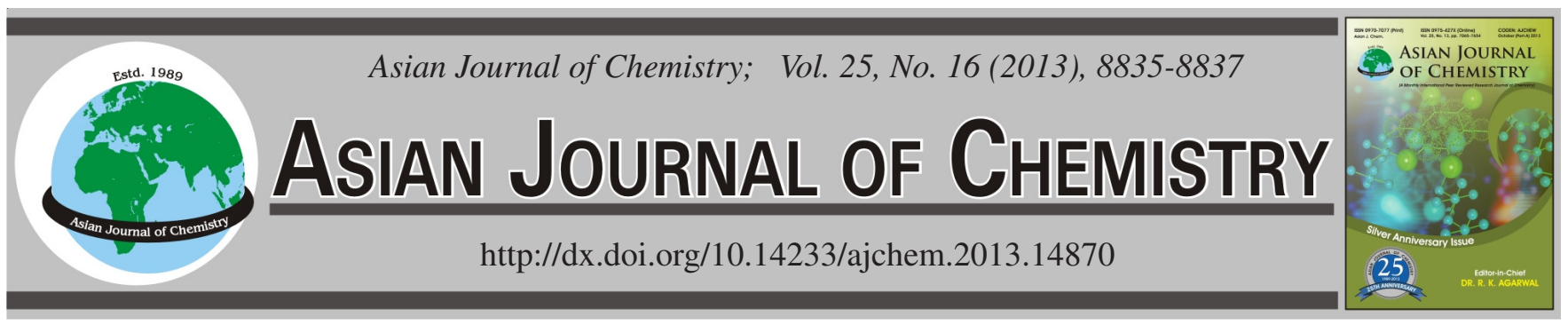

\title{
REVIEW
}

\section{Chemical Environment Influence the Incidence of Childhood Autism}

\author{
Rong-Rong Yu*, Yun Xu, Yong-Gu Wang and FeI-Yue Qiu*
}

School of Education Science and Technology, Zhejiang University of Technology, Hangzhou 310032, P.R. China

*Corresponding authors: Fax: +86 571 86404225; Tel: +86 571 86404073; E-mail: libin0571@ zju.edu.cn; qfy@zjut.edu.cn

This review summarizes the environmental factors in particular chemicals involved in autism with either increasing or reducing effect in disease incidence, which will be helpful for prevention and treatment of the disease.

Key Words: Chemicals, Autism, Incidence, Prevention.

\section{INTRODUCTION}

Study on etiology of childhood autism has always been a challenge for medical research. More and more researchers in this field agreed that autism is a biologically based disease, while genetic or gene abnormality may be the main reason of childhood autism ${ }^{1-6}$. Nowadays, most studies of autism have linked the etiology to genetics, but simple genetic etiology is difficult to explain the complexity and diversity of autism in children. Interestingly, many recent studies have indicated that the chemical environmental factors may be involved in the development of childhood autism. In many cases, genes or chemical environment alone may not be sufficient to cause autism, interactions of both them may increase prevalence of autism in children ${ }^{7-9}$. In order to clear the role of chemical environments in the etiology of autism, this article gives a comprehensive analysis in effects of chemical factors, genetic factors alone or both in combination on childhood autism, which may be able to provide new strategies for prevention and treatment of the disease.

Genetic basis of autism: Genetics of autism is an indisputable fact. The high relevance between childhood autism and genetic factors has been confirmed by epidemiological investigation and twin studies. Identical twins were suffering from autism probability of 60-80\%. However, fraternal twins were suffering from autism probability of 3-10\%, while compatriot patients have an illness probability of 3-5 $\%^{5}$. This data is significantly higher than that of Yu et al. ${ }^{3}$ survey, who found that there was a $2.6 \%$ incidence of autism in the normal population in China. Furthermore, the genetics of autism was also able to be confirmed by the results from the researches of genomic imbalances, if the parents are carriers of the genomic imbalances, the probability of children with genomic imbalances was as high as $50 \%$. However, if the parents are not carriers of the genomic imbalances, the probability of children with genomic imbalances was about $0.1 \%{ }^{4}$, which is similar to other groups.

Factors affecting autism genetics: Most studies have found that genes play a major role in the etiology of autism. In particular, as the application of many technologies, such as genome scan, gene chip and fluorescence in situ hybrid, more and more autism related genes have been gradually reported ${ }^{5,6}$. However, almost no gene has been determined to be specifically responsible for autism and can be stability copied. In addition, a gene from different investigation population may have full different results. This indicated that the disease is genetic complex and multiple different genes may be involved in the etiology of autism, while the role of each gene is small. Inspection of the relationship between single gene and disease may be difficult to reach a significance level.

A specific gene mutation, deletion, or a set of specific gene polymorphisms may be predisposing factors for autism. Indeed, it has been well known that autism is not a singlegene genetic disease, but rather a complex disease, with or without the gene only a risk factor and need to act in some specific environmental conditions. Therefore, these results indicated that the environment factors may have an important impact in the formation and development of autism. However, most current studies focus on genetic factors, which is mainly because it is difficult to quantify, control and compare most of the environmental factors. Some researchers have suggested using epidemiological methods, in combination with hypothesis testing ideas to study the relationship between prenatal risk 
environmental factors and autism. In addition, the population with the same genetic background was choosed for the researches of autism under different growth and development environment ${ }^{4}$.

Influence of chemical environment: The latest researches in childhood autism has slowly shifted from just concerned about the genetics to more and more focus on environment in which played an important role $e^{7-30}$. The survey found that the autism risk increased by $6 \%$ when conceive in the winter (December, January or February) compare to conceive in July, which provide the legitimate evidence for this research of environmental factors role in autism ${ }^{10}$. In addition, environmental exposure may affect the neurodevelopment by a variety of ways, either through direct effects for example neurotoxicity or through indirect effects such as changing the composition of fetal cells so as to increase exposure susceptibility to specific environment ${ }^{7-9}$. A large number of clinical and research results support that environmental effects may affect the development of brain, other organs and systems, as well as ongoing physiological process, in particular, the immune dysfunction and the increased vulnerability of immune system ${ }^{7-9}$.

Table-1 shows the wide range of environmental factors, which have been postulated to be the causes or trigger agents for fetal or early neonatal autism. Many researchers have proposed to re-examine this complex and mysterious disease by focusing on strong genetic risk factors. The studies have shown that fetal chromosomal is sensitive to chemicals, which may result in dysfunctional consequences of child development, such as in the early stages of pregnancy exposure to antiepileptic drug valproic acid, has been shown to increase the risk of neural tube defects in the fetal period and then increased the risk of autism ${ }^{7}$. Environmental drugs were able to cause the hypermethylation and histone deacetylation conversion, which resulted in a cascade of events, such as changes in gene expression or decrease in glutathione activity in the critical period of development, so that the cells are able to be damaged by induce oxidative stress ${ }^{7}$. Common environmental factors can cause autism includes the infection of vaccine, the mercury preservative in vaccines, parents' age, lack of folic acid or other non-genetic carbon units metabolic disorders, hypocholesterolemia, exposure to prenatal testosterone and excessive active immune system ${ }^{8}$.

Studies have shown that periconceptional, such as from one month before conception to three months after conception, need at least to supplement the prenatal vitamins each week, which are able to reduce the occurrence probability of autism by $40 \%$. The effect of prenatal vitamin use is closely related to the dose and the more significant for the genetic predisposition of the mother and child. In the United States and other countries through the use of folic acid to reduce the occurrence probability of neural tube defects caused by the use of antiepileptic drug valproic acid. This may be because that folic acid is a key factor in the one-carbon metabolism, which may be able to provide the methyl for genomic modification.

Children with autism and their parents share similar metabolic defects, such as methylation capacity, glutathionedependent antioxidant and detoxification capacity that observed in many children with autism ${ }^{8}$. Autistic children have changed the metabolism of heavy metals and xenobiotic toxicity. Reduction in the ratio of zinc and copper may reveal the lack of metallothionein function, resulting in impaired metal binding and increased vulnerability to metal toxicity ${ }^{8}$. In addition, dietary factors and food contaminants may also pose a risk, in particular, the intake of $\omega-3$ fatty acids and human health, as well as the intestinal flora is also being considered as the environmental factors that influence the incidence of childhood autism. But some basic biochemical disturbances (such as abnormal in glutathione and detoxification, as well as a key antioxidant) can be reversed through targeted nutrition interventions.

\begin{tabular}{|c|c|c|}
\hline \multicolumn{3}{|c|}{$\begin{array}{c}\text { TABLE-1 } \\
\text { CHEMICAL ENVIRONMENTAL FACTORS AFFECT } \\
\text { THE INCIDENCE OF CHILDHOOD AUTISM }\end{array}$} \\
\hline Chemical factors & Autism incidence & References \\
\hline Prenatal vitamin & Decrease & $7-9,11$ \\
\hline Folic acid & Decrease & $7-9,11$ \\
\hline Valproic acid & Increase & 7 \\
\hline Cadmium & Increase & 7,12 \\
\hline Arsenic & Increase & 7,12 \\
\hline Organochlorine pesticides & Increase & 7,12 \\
\hline Vaccine preservatives & Increase & $7-9,13,14$ \\
\hline Vaccine chemical toxins & Increase & 7 \\
\hline Vaccine live virus & Increase & 7 \\
\hline Herb horsetail & Increase & 15 \\
\hline Alcohol & Increase & 15 \\
\hline Environmental hormones & Increase & 16 \\
\hline Vinyl chloride the phthalates floor & Increase & 17 \\
\hline The mother smoking & Increase & 17 \\
\hline Air circulation & Increase & 17 \\
\hline Industrial chemicals & Increase & 18 \\
\hline Methyl cobalamin & Decrease & 8 \\
\hline Acetaminophen & Increase & 8,19 \\
\hline Winter conception & Increase & 10,30 \\
\hline Prenatal testosterone & Increase & $9,13,14$ \\
\hline$\omega-3$ Fatty acid deficiency & Increase & 8,20 \\
\hline Propionate & Increase & 8,21 \\
\hline Air pollution & Increase & 8 \\
\hline Organic phosphorus & Increase & 8 \\
\hline Heavy metals & Increase & 8 \\
\hline Parental age & - & 9 \\
\hline Mercury & Increase & $7-9,22$ \\
\hline Nickel & Increase & 8,22 \\
\hline Trichlorethylene & Increase & 8,22 \\
\hline Cloroethylene & Increase & 8,22 \\
\hline Human health & - & 8 \\
\hline Intestinal microorganisms & - & 8 \\
\hline Vitamin D deficiency & Increase & 23 \\
\hline
\end{tabular}

Environment and gene interactions: Model has been established to investigate the role of gene-environment interactions in a retrospective case studies ${ }^{7,8}$. Interestingly, mice that injected with propionic acid (the main byproduct of Clostridium and as a common food preservative) caused social isolation and reduction in play behaviour, as well as oxidative stress and other symptoms, these disorders are similar to the symptom of autism. This model system may be applicable to many other environmental exposures ${ }^{8}$. Because many studies being carried out by collecting a quite large population of biological and environmental data. Using this method, it 
will be helpful for us to capture the key neurodevelopmental time that related to the variation of human gene expression. These results provide a basis for clarifying the epidemiology of children with autism, opening a way to elucidate the mystery of this complex disease. However, it will need take a quite long time to track, observe and compare the difference between the normal and autism population ${ }^{7}$.

The pathophysiology of systemic and central nervous system, including oxidative stress, neuroinflammation and mitochondrial dysfunction is consistent with the role of air pollution, organic phosphorus, heavy metals and other environmental factors in autism. Chemical exposure and heredity may result in the same molecular, cellular and behavioural outcomes, especially the interference of three neurotransmitters and pathways, such as $\gamma$-aminobutyric acid, acetylcholine and calcium signal transduction pathway and a calcium-dependent effect of environment preparation ${ }^{8}$. The genetic variation in autism patients caused the increased vulnerability to environmental stress and exposure. In addition, because of the genetic causes, the innate genetic weaknesses for autism children may lower the threshold, which will make the environmental factors significant. Expose to mercury, cadmium, nickel, trichlorethylene and vinyl chloride and other environmental mutagens during preconception can cause an increased risk of autism and the influence of these substances may be aggravated by the lack of vitamin D, which plays an important role in the DNA repair mechanism ${ }^{8}$. With the growing number of environmental factors or sensitive genes and pathways, comparative toxicogenomics database is becoming increasingly valuable.

Complex interactions between autism genes and the environment has been partially confirmed, such as the accumulation ways of folic acid are often affected by the child development time and the genetic variation that caused by prenatal vitamins and many other factors. Some current research of autism focused on the children's genes, however, the autism may be affected by both prenatal child and maternal environment. Therefore, it is worth to pay more attention to study maternal genotype during perinatal environment. Although the genes played an important role in the formation of autism, but it looks like the genetic characteristics was not responsible for common mutation in a large and independent main effect. In fact, based on the release data of the latest genome-wide scan, a handful sites have reached genome-wide significance and that unavailable for copy may reflect a complex networks between multi-genes and cohesive environment ${ }^{7}$.

Although it is important to understand the etiology of childhood autism, little information could be obtained on this interaction between genes and the environment in particular chemical factors. Until recently, few reports have been observed in some research articles, which focus on the effects of genes or environment alone ${ }^{7}$. Although the interactions between chemical environmental factors and genetic can provide fertile soil to carry out a challenging and interdisciplinary cooperation, but the forward-looking research is still in its infancy. It is necessary to further collect data of perinatal drug, chemical exposure and genetic, identify the important genes and their correlation with chemical factors from large population stocks, which will be important for clearing the chemical etiology and epidemiology of autism.

\section{ACKNOWLEDGEMENTS}

This work was supported by The Ministry of Education of Humanities and Social Science Project (10YJCXLX053), Zhejiang Provincial Natural Science Foundation of China (LQ12H09005), the Fundamental "Zhijiang Qingnian" Research of Zhejiang Provincial Philosophy and Social Science Foundation of China (11ZJQN065YB), Zhejiang Provincial Ministry of education of Humanities and Social Science Project (Y201018729); Project supported by the Major Program of the National Social Science Foundation of China (12\&ZD229), Projects in the National Science \& Technology Pillar Program (2012BAI34B02, 2012BAI34B03).

\section{REFERENCES}

1. F. Zhang, X. Sui, J. Wang, S. Xue, X.Q. Lu, X.J. Ma and X. Zhu, Mater. Child Health Care China, 23, 3878 (2008).

2. J. Zhang, C.Q. Xu and J.R. Zhang, Mater. Child Health Care China, 20, 2395 (2005).

3. R.R. Yu, L.H. Lin, D. Xu, X. Li and F.Y. Qiu, Mater. Child Health Care China, 29, 4563 (2011).

4. B.L. Wu, X.B. Zou and X. Xu, Chin. J. Evid-based Pediatr., 3, 241 (2008).

5. P. Shi, J. Clin. Psychiatry, 17, 134 (2007).

6. K.Z. Liu, X.M. Liang and L.T. Guo, J. Appl. Clin. Pediatr., 25, 1768 (2010).

7. S.M. Engel and J.L. Daniels, Epidemiology, 22, 486 (2011).

8. M.R. Herbert, Curr. Opin. Neurol., 23, 103 (2010).

9. C. Stoltenberg, Epidemiology, 22, 489 (2011).

10. I. Hertz-Picciotto, L.A. Croen, R. Hansen, C.R. Jones, J. van de Water and I.N. Pessah, Environ. Health Perspect., 114, 1119 (2006).

11. R.J. Schmidt, R.L. Hansen, J. Hartiala, H. Allayee, L.C. Schmidt, D.J. Tancredi, F. Tassone and I. Hertz-Picciotto, Epidemiology, 22, 476 (2011).

12. K.Y. Kim, D.S. Kim, S.K. Lee, I.K. Lee, J.H. Kang, Y.S. Chang, D.R. Jacobs, M. Steffes and D.H. Lee, Environ. Health Perspect, 118, 370 (2010).

13. B.S. Abrahams and D.H. Geschwind, Nat. Rev. Genet., 9, 341 (2008).

14. M.L. Rutter, J. Autism Dev. Disord., 41, 395 (2011).

15. J.A. Ortega García, M.G. Angulo, E.J. Sobrino-Najul, O.P. Soldin, A.P. Mira, E. Martínez-Salcedo and L. Claudio, J. Med. Case Reports, 5, 129 (2011).

16. M. Kajta and A. Wojtowicz, Przegl. Lek., 67, 1194 (2010).

17. M. Larsson, B. Weiss, S. Janson, J. Sundell and C.G. Bornehag, Neurotoxicology, 30, 822 (2009).

18. D. Labie, Med. Sci. (Paris), 23, 868 (2007).

19. K.G. Becker and S.T. Schultz, Med. Hypotheses, 74, 7 (2010).

20. M.D. Valicenti-McDermott, K. McVicar, H.J. Cohen, B.K. Wershil and S. Shinnar, Pediatr. Neurol., 39, 392 (2008).

21. S.R. Shultz, D.F. MacFabe, K.P. Ossenkopp, S. Scratch, J. Whelan, R. Taylor and D.P. Cain, Neuropharmacology, 54, 901 (2008).

22. D.K. Kinney, D.H. Barch, B. Chayka, S. Napoleon and K.M. Munir, Med. Hypotheses, 74, 102 (2010).

23. J.J. Cannell, Med. Hypoth., 70, 750 (2008).

24. F. Perera and J. Herbstman, Reprod. Toxicol., 31, 363 (2011).

25. M.B. Lauritsen, C. Obel, P.B. Mortensen and J. Olsen, Ugeskr. Laeger, 162, 1403 (2000).

26. E. London and R.A. Etzel, Environ. Health Perspect., 108, 401 (2000).

27. M. D'Amelio, I. Ricci, R. Sacco, X. Liu, L. D'Agruma, L.A. Muscarella, V. Guarnieri, R. Militerni, C. Bravaccio, M. Elia, C. Schneider, R. Melmed, S. Trillo, T. Pascucci, S. Puglisi-Allegra, K.L. Reichelt, F, Macciardi, J.J. Holden and A.M. Persico, Mol. Psychiatry, 10, 1006 (2005).

28. B.M. Altevogt, S.L. Hanson and A.I. Leshner, Pediatrics, 121, 1225 (2008).

29. C. Stoltenberg, S. Schjolberg, M. Bresnahan, M. Hornig, D. Hirtz, C. Dahl, K.K. Lie, T. Reichborn-Kjennerud, P. Schreuder, E. Alsaker, A.S. Øyen, P. Magnus, P. Surén, E. Susser, W.O. Lipkin and ABC Study Group., Mol. Psychiatry, 15, 676 (2010).

30. O. Zerbo, A.M. Iosif, L. Delwiche, C. Walker and I. Hertz-Picciotto, Epidemiology, 22, 469 (2011). 